\title{
GOVERNANÇA AMBIENTAL NO BRASIL: RUMO AOS OBJETIVOS DO DESENVOLVIMENTO SUSTENTÁVEL (ODS)?
}

\author{
Environmental Governance in Brazil: towards the Sustainable Development Goals (SDGs)?
}

\author{
Gobernanza Ambiental en Brasil: ¿Hacia los Objetivos de Desarrollo Sostenible (ODS)?
}

\section{RESUMO}

A governança ambiental é peça-chave para atingir a Agenda 2030 da Organização das Nações Unidas (ONU). Este artigo explora o potencial do Brasil de aproximar-se dos Objetivos do Desenvolvimento Sustentável (ODS) da Agenda 2030. Para tanto, apresenta seus avanços e retrocessos, em particular após a Constituição Federal de 1988 enfocando: licenciamento ambiental; vegetação nativa; recursos pesqueiros; recursos hídricos; unidades de conservação; e mudanças climáticas. Concluímos o artigo apontando que os retrocessos impostos ao sistema de governança ambiental na última década, e principalmente no último ano, indicam que o país caminha em direção oposta ao futuro almejado pela Agenda 2030.

PALAVRAS-CHAVE: licenciamento ambiental, código florestal, recursos hídricos, recursos pesqueiros, unidades de conservação, mudanças climáticas

Cristiana Simão Seixas ${ }^{1}$

csseixas@unicamp.br

https://orcid.org/0000-0002-4464-2094

Deborah Santos Prado 2

deborah.stprado@yahoo.com.br

https://orcid.org/0000-0002-4671-8507

Carlos Alfredo Joly ${ }^{3}$

cjoly@unicamp.br

https://orcid.org/0000-0002-7945-2805

Peter Herman May ${ }^{4}$

peterhmay@gmail.com

https://orcid.org/0000-0003-3535-8363

Estela M. Souza Costa Neves ${ }^{5}$

estela.neves@terra.com.br

https://orcid.org/0000-0002-5053-3193

Leonardo Ribeiro Teixeira ${ }^{6}$

leoibama@hotmail.com

http://orcid.org/0000-0001-5336-9109

1. Universidade Estadual de Campinas, Núcleo de Estudos e Pesquisas Ambientais, SP, Brasil.

2. Universidade Estadual de Campinas, Grupo de Pesquisa e Extensão em Conservação e Gestão de Recursos Comuns, SP, Brasil.

3. Universidade Estadual de Campinas, Instituto de Biologia, SP, Brasil.

4. Universidade Federal Rural do Rio de Janeiro, Departamento de Desenvolvimento, Agricultura e Sociedade, RJ, Brasil.

5. Universidade Federal do Rio de Janeiro, Programa de Pós Graduação em Políticas Públicas, Estratégias e Desenvolvimento - PPED/ Instituto de Economia, RJ, Brasil

6. Instituto Brasileiro de Meio Ambiente e Recursos Naturais (IBAMA), SP, Brasil.

Artigo convidado

DOI: http://dx.doi.org/10.12660/cgpc.v25n81.81404 
Cristiana Simão Seixas - Deborah Santos Prado - Carlos Alfredo Joly - Peter Herman May - Estela M. Souza Costa Neves - Leonardo Ribeiro Teixeira

\section{ABSTRACT}

Environmental governance is key to achieving the United Nations 2030 Agenda. This article explores Brazil's potential to address the 2030 Agenda Sustainable Development Goals. To do so, it presents Brazil's advances and setbacks, particularly after the 1988 Federal Constitution, focusing on: environmental licensing, native vegetation, fishing resources, water resources, protected areas and climate change. We conclude the article by pointing out that the setbacks imposed on the environmental governance system over the last decade, and especially in the last year, indicate that the country is moving in a direction opposite to that of the future envisaged by Agenda 2030.

KEY-WORDS: environmental licensing, forest code, water resources, fishing resources, protected areas, climate change

\section{RESUMEN}

La gobernanza ambiental es clave para lograr la Agenda 2030 de las Naciones Unidas. Este artículo explora el potencial de Brasil para acercarse a los Objetivos de Desarrollo Sostenible de la Agenda 2030. Para esto, presenta sus avances y retrocesos, particularmente después de la Constitución Federal de 1988, centrándose en: licencias ambientales, vegetación nativa, recursos pesqueros, recurșos hídricos, áreas protegidas y cambio climático. Concluimos el artículo señalando que los reveses impuestos al sistema de gobernanza ambiental en la última década, y especialmente el último año, indican que el país se está moviendo en dirección opuesta al futuro previsto por la Agenda 2030.

PALABRAS CLAVE: licencia ambiental, código forestal, recursos hídricos, recursos pesqueros, áreas protegidas, cambio climático

\section{INTRODUÇÃO}

A governança ambiental pode ser entendida como um processo envolvendo múltiplos atores sociais e seus respectivos valores e interesses na elaboração, tomada de decisão e implementação de ações que visam à conservação ambiental (Folke, Hahn, Olsson, \& Norberg, 2005; Kooiman \& Bavinck, 2005; Lemos \& Agrawal, 2006). É composta tanto pela estrutura institucional formal (ex., políticas públicas, conselhos gestores, áreas protegidas), como por arranjos institucionais informais (ex. pactos, coalizões, movimentos sociais) envolvendo, além de organizações governamentais, a sociedade civil organizada e o setor privado, atuando em diversos níveis de organização sociopolítica - do local ao global. Portanto, é um termo amplo que pode englobar processos de gestão, gerenciamento e manejo (Seixas, Vieira, Medeiros, Quevedo \& Zerafini, 2020) Os valores, princípios e objetivos da governança ambiental são negociados e, portan- to, não são estáveis - como no caso da gestão, do gerenciamento e do manejo -, mas variam de acordo com a participação relativa dos atores que entram e saem do processo (Chuenpagdee \& Jentoft, 2009). A governança ambiental pode enfocar tanto as ações de conservação e uso sustentável da biodiversidade e serviços ecossistêmicos (tais como água e regulação climática), como as de remediação dos impactos das atividades humanas sobre a biodiversidade e os serviços ecossistêmicos. Em nível global, os esforços de governança ambiental na atualidade têm como foco os 17 ODS e suas 169 metas que compõem a Agenda 2030 da ONU. A construção desta agenda, que se iniciou durante a Rio +20, teve forte protagonismo do Brasil, e foi adotada por 193 países na Cúpula das Nações Unidas para o Desenvolvimento Sustentável, em 2015.

Neste sentido, este artigo busca apresentar os avanços e retrocessos, em particular após a Constituição Federal de 1988, da go- 
vernança ambiental no Brasil, explorando os potenciais do país de aproximar-se dos ODS (ONU 2015). Para tanto, enfocaremos aspectos relacionados a: licenciamento ambiental; vegetação nativa; recursos pesqueiros; recursos hídricos; unidades de conservação; e questão climática. Nosso foco será nas instituições formais (leis, decretos, planos, programas etc.) e instituições informais (coalizões, movimentos sociais etc.) que atuam na governança ambiental no Brasil. Concluímos o artigo apontando os desafios mais recentes para aproximar o país da Agenda 2030.

\section{LICENCIAMENTO AMBIENTAL}

Entre os instrumentos criados para a implementação da Política Nacional do Meio Ambiente (Lei n. $6.938 / 1981$ ) estão a Avaliação de Impacto Ambiental (AIA) e o Licenciamento Ambiental para as atividades consideradas efetiva ou potencialmente poluidoras. Por meio destes, o Estado exerce controle sobre as atividades humanas com efeitos significativos nas condições ambientais, tendo (teoricamente) como princípio a conciliação do desenvolvimento econômico com o uso dos recursos naturais, assegurando o uso não depredatório dos ecossistemas em suas dimensões física, biótica e socioeconômica. Ainda na década de 1980, - Conselho Nacional de Meio Ambiente (CONAMA) publicou a Resolução CONAMA 01/1986, com os critérios básicos e as diretrizes gerais para uso e implementação da AIA, conforme recomendavam as convenções internacionais.

O artigo 225 da Constituição Federal de 1988 destaca o estudo prévio de impacto ambiental como exigência para instalação de obra ou atividade potencialmente causadora de significativa degradação ambiental. Além disso, determina em seu artigo 23 que a proteção do meio ambiente, o controle da poluição, a preservação das florestas, da fauna e da flora são de competência comum da União, dos Estados, do Distrito Federal e dos municípios. Entretanto, somente em 2011, com a edição da Lei Complementar n. $-140 / 2011$, é que a distribuição de competências de licenciamento ambiental foi claramente estabelecida. A edição dessa lei replicou, com alguns ajustes, parte das definições anteriormente presentes na Resolução CONAMA 237/97. De forma genérica, a combinação desses regramentos (CONAMA 01/1986, CONAMA 237/1997 e Lei Complementar $n . .9140 / 2011$ ) com algumas regulamentações específicas funciona como base legal para o desenvolvimento do processo de licenciamento e para a AIA no Brasil. Considerando o poder de grandes empreendimentos de infraestrutura na transformação (ambiental e socioeconômica) de territórios, os efeitos indiretos de eventuais alterações nesse compilado normativo alcançam cada cidadão brasileiro, afetando, em muitos casos, outros países.

\section{Avanços}

Desde o início dos anos 2000, quando um grupo de instituições financeiras responsáveis por $70 \%$ do total de investimentos no mundo lançou os "Princípios do Equador" (Dias \& Machado, 2007), o mercado tem tido um importante papel regulatório para a agenda do licenciamento ambiental. Ressalvados os limites para essa regulação em uma Sociedade de Risco (Beck, Lash \& Wynne, 1992), a postura do mercado pode ser um elemento-chave em um momento de 
discussão sobre o aperfeiçoamento do processo de licenciamento.

A consolidação da Associação Brasileira de Avaliação de Impacto Ambiental (ABAI), criada em 2011, como entidade coordenadora de iniciativas e difusora de informações qualificadas sobre o tema, tem contribuído para a elevação do nível do debate no país. A entidade possui estreito relacionamento com seus pares internacionais, como a International Association for Impact Assessment (IAIA), promovendo a troca de experiências entre diferentes realidades onde a AIA é aplicada. A ABAI mantém uma forte relação com as universidades protagonistas nas análises das falhas, dos avanços, dos indicadores e das recomendações para o aprimoramento do processo de licenciamento.

Entre as medidas inovadoras e replicáveis, destaca-se o desenvolvimento do Projeto de Avaliação de Impactos Cumulativos (PAIC) no litoral paulista e fluminense. Como condicionante das licenças ambientais dos projetos integrados do pré-sal, o Instituto Brasileiro do Meio Ambiente e dos Recursos Naturais (IBAMA) elaborou, em conjunto com a Petrobras, um projeto com o objetivo de aferir e mitigar os efeitos da sobreposição das atividades licenciadas com outros estressores, de origem natural e antrópica (https://www.comunicabaciadesantos.com. br/programa-ambiental/projeto-de-avaliacao-de-impactos-cumulativos-paic.html).

\section{Limitações e retrocessos}

Entre as principais dificuldades de aplicação do dueto AIA - Licenciamento, no Brasil, estão: falta de clareza na definição do escopo da análise e padronização dos termos de referência; subjetividade na tomada de decisão; construção de protocolos de participação pública mais justos e eficazes; articulação com outros instrumentos de gestão territorial (zoneamento econômico-ecológico, planos de bacia hidrográficas, planos diretores municipais); desconsideração dos efeitos cumulativos; ausência de instrumentos complementares de avaliação (como a Avaliação Ambiental Estratégica (AEE) ou a Avaliação de Impactos Cumulativos); falta de recursos dos órgãos licenciadores; e baixa qualidade dos estudos apresentados pelos empreendedores (CEBDS, 2019; Fonseca, Sánchez, Montano, Souza \& Almeida, 2019; Hofmann, 2015). Contudo, estas limitações precisam ser colocadas em contexto para evitar a disseminação de críticas generalistas que comprometem inclusive a opinião pública.

Há necessidade de uma série de aprimoramentos nos instrumentos de licenciamento e AIA (Fonseca, Sánchez \& Ribeiro, 2017). Desde 2004, tramita no Congresso Nacional uma proposta de "Lei Geral do Licenciamento Ambiental", que tem como objetivo regulamentar o inciso IV do $\S 1^{\circ}$ do art. 225 da Constituição Federal, modificando e consolidando as principais regras do licenciamento em um único regramento, buscando a redução de prazos de concessão de licenças e flexibilizações para algumas atividades, atualmente, sujeitas ao rito completo de avaliação de impactos. Os debates públicos têm sido acalorados e, muitas vezes, seguem um padrão simplista e binário, colocando "ambientalistas" e "desenvolvimentistas" em lados opostos. Assim, tratando-se de um tema singular, que carece de conhecimento técnico e de tradução para os debatedores, a comunidade científica tem se posicionado 
assertivamente, buscando a construção de consensos e subsidiando os tomadores de decisão com o conhecimento acumulado ao longo de 50 anos de pesquisas sobre o tema (Fonseca et al., 2019; Sánchez, Fonseca \& Montano, 2019).

Segundo Sánchez et al. (2019), a análise da terceira versão do Projeto de Lei Geral do Licenciamento Ambiental evidencia uma tendência de simplificação do tema, cujo texto-base carrega uma série de fragilidades, que vão desde a desconsideração dos impactos indiretos na AIA, até a indiferença em relação à capacidade técnica e material dos órgãos licenciadores para implementação da própria lei. Essa simplificação tende a gerar mais dificuldades, judicializações e atrasos nos processos de licenciamento.

A modernização dos instrumentos de AIA e licenciamento é necessária para garantir a disponibilidade e o manejo sustentável da água, a ampliação da infraestrutura de saneamento (ODS 6), a geração e a distribuição de energia limpa e barata (ODS 7), bem como para prover o país com um sistema energético e de transportes resiliente $e$ inteligente (ODS 9). Nesse caso, a inserção da variável ambiental em níveis introdutórios à tomada de decisão, como nas políticas, planos e programas, por meio da adoção da $A A E$, possibilitaria leituras integradoras dos impactos dos projetos, aumentando a compreensão de seus efeitos socioambientais, simplificando as AIAs e, consequentemente, o tempo de análise.

\section{VEGETAÇÃO NATIVA: RESERVA LEGAL E ÁREAS DE PROTEÇÃO PERMANENTE}

O Código Florestal de 1934 criou a Reserva
Legal, ao exigir que os proprietários rurais mantivessem $25 \%$ da área de seus imóveis com a cobertura de mata original. Criou também a figura das florestas protetoras, para garantir a saúde de rios e lagos e áreas de risco. Mais tarde, esse conceito deu origem às Áreas de Preservação Permanente (Drummond, 1999). Entretanto, como outras tantas, esta legislação "não pegou", não sendo de fato implantada.

O Código Florestal de 1965 tutelava, além das florestas, as demais formas de vegetação. Esta lei consolidou os conceitos de Reserva Legal (RL) e de Áreas de Preservação Permanente (APP): "RL é a área localizada no interior de uma propriedade ou posse rural, excetuada a de preservação permanente, necessária ao uso sustentável dos recursos naturais, à conservação e reabilitação dos processos ecológicos e à conservação da biodiversidade. APP é uma área protegida, coberta ou não por vegetação nativa, com a função ambiental de preservar os recursos hídricos, a paisagem, a estabilidade geológica, a biodiversidade, o fluxo gênico de fauna e flora, proteger o solo e assegurar o bem-estar das populações humanas."

Esse Código estabeleceu ainda que nas regiões Sul, Sudeste e Centro-Oeste a RL seria de $20 \%$ da propriedade, e nas áreas de floresta da Região Norte e parte da Centro-Oeste o percentual seria de $50 \%$.

Mas, infelizmente, o Código de 1965 também não trouxe instrumentos que o fizessem sair, de fato, do papel. A criação do Instituto Brasileiro de Desenvolvimento Florestal (IBDF), em 1967, foi tida como sua única ação realmente eficaz (Pasqualetto, 2011). 


\section{Avanços}

Código Florestal de 1965 foi alterado por algumas leis, sempre no sentido de ampliar a proteção ambiental das RLs e APPs. O "Pacote Verde" do governo Sarney ampliou as APPs estabelecendo a largura mínima de 30 metros para os cursos d'água de menos de 10 metros de largura, e pela primeira vez menciona, explicitamente, que a legislação se refere a todas as formas de vegetação nativa, não só à florestal (Lei n.․․ 7.803 de 1989). Frente às altas taxas de desmatamento da Amazônia, que atingiram a marca de 29 mil Km2 em 1995, o governo Fernando Henrique Cardoso, através de Medida Provisória (MP n. 1.511 de 1996), ampliou a $\mathrm{RL}$ para $80 \%$ nas propriedades constituídas por fitofisionomias florestais da Região Norte, norte da Região Centro-Oeste e oeste do Estado do Maranhão. Nesta mesma região, a RL em propriedades constituídas por fisionomias de Cerrado passou a ser de $35 \%$.

Durante os 16 anos de vigência desta MP, várias iniciativas não governamentais começaram a reverter o quadro de degradação da vegetação nativa. Dentre estas, destacamos o Pacto pela Restauração da Mata Atlântica, a Aliança pela Restauração da Amazônia e a Rede de Sementes do Xingu. Organizações como o Instituto Socioambiental, a Rede Cerrado e as redes de sementes crioulas, mobilizadas pelos movimentos em torno da agroecologia em diversos biomas, também estimularam a circulação de sementes, visando a manter a variabilidade genética de espécies nativas cultivadas.

Além disso, houve avanços no monitoramento de alterações da cobertura vegetal nativa.
O Instituto Nacional de Pesquisas Espaciais (INPE), com os Programas Deter e Prodes, possui papel importantíssimo neste quesito. Entretanto, a mais completa ferramenta de acesso público e gratuito, o Mapbioma, não é governamental, mas sim continuamente desenvolvido e aperfeiçoado por uma rede colaborativa que envolve ONGs, universidades e empresas de tecnologia. Há também o Observatório do Código Florestal - uma rede de 30 instituições não governamentais -, que gera dados e massa crítica sobre a implementação da Lei n.ำ 12.651/2012 de Proteção da Vegetação Nativa (LPVN).

A discussão sobre a atualização do Código Florestal de 1965 começou em 1999, e diversas iniciativas foram apresentadas pelos parlamentares. Em 2009, uma Comissão Especial da Câmara dos Deputados analisou as 12 propostas que tramitavam sobre $o$ tema, mas ignorou todas as recomendações feitas pelo Grupo de Trabalho Código Florestal da Sociedade Brasileira para o Progresso da Ciência \& Academia Brasileira de Ciências (GT SBPC \& ABC) (SPBC 2012). Em 2011, o Senado aprovou um texto substitutivo (PLC 30/2011), incorporando diversas recomendações feitas pelo grupo, mas, no retorno à Câmara dos Deputados, todas foram descartadas e o texto final foi aprovado em $25 / 04 / 2012$. Finalmente, às vésperas da Rio +20 , a presidente Dilma Roussef sancionou a LPVN sem nenhum veto e, em 28/02/2018, o Supremo Tribunal Federal julgou constitucionais praticamente todos os dispositivos aprovados pela Câmara.

\section{Limitações e retrocessos}

A LPVN é, atualmente, o principal instrumento legal para proteção da vegetação nativa 
em áreas privadas, através da obrigatoriedade de preservar ou restaurar as áreas de $\mathrm{RL}$ e APPs nas propriedades. Entretanto, seu Artigo 68 elimina a obrigação de recomposição ou restauração da vegetação nativa convertida em área agro-silvo-pastoril sem violação da lei vigente à época da conversão, desde que o proprietário se registre no Cadastro Ambiental Rural (CAR) e adira ao Programa de Regularização Fundiária (PRA). O inciso IV do artigo $3^{\circ}$ da LPVN define 22/06/2008 como a data para reconhecer a consolidação da ocupação de uma área rural, ou seja, garantiu a impunidade de crimes cometidos ao longo de décadas. Esta, e outras brechas, têm permitido um gradativo afrouxamento da obrigatoriedade de restauração da vegetação nativa em propriedades agrícolas.

Os mecanismos de anistia da LPVN reduziram o passivo de APPs e RLs em, respectivamente, 4,5 milhões ha e 36,5 milhões ha de vegetação nativa que deveriam ser restaurados (Guidotti, Freitas, Sparovek, Pinto, Hamamura, Carvalho \& Cerignoni, 2017). Apesar de a área total de restauração de $\mathrm{RL}$ e APP anistiada ter sido maior na Região Amazônica, em termos relativos a Mata Atlântica foi o bioma mais impactado pelos mecanismos de anistia (Brancalion, Garcia, Loyola, Rodrigues, Pillar \& Lewinsohn, 2016).

Em 17/10/2012, foi editado o Decreto n. 7.830/2012 para regulamentar o CAR e o Sistema de Cadastro Ambiental Rural (SICAR), e criar normas de caráter geral do PRA. O registro da propriedade no CAR passou a ser requisito indispensável para adesão ao PRA, que permite não só a obtenção de crédito agrícola, mas também converter eventuais multas de desmatamento da APP e da RL em serviços ambientais; computar a APP no cálculo da $R L$ do imóvel (confundindo dois instrumentos com funções ecológicas completamente distintas) (Metzger et al. 2019); fazer a restauração da $R L$ em outra propriedade dentro do mesmo bioma (ignorando que o serviço ecossistêmico é necessário na sub-bacia e bacia onde a remoção ilegal da vegetação nativa ocorreu); e recompor até $50 \%$ da RL com espécies exóticas. Aderindo ao PRA, pequenas propriedades de até quatro módulos fiscais (medida que varia de 20 ha a 400 ha de acordo com a região) estão isentas de recuperar a $R L$ e têm a faixa de APP reduzida de $30 \mathrm{~m}$ para $15 \mathrm{~m}$ em cada margem, no caso de rios com menos de $10 \mathrm{~m}$ de largura.

O prazo para registro no CAR, primeira e fundamental etapa para o PRA, foi sendo sistematicamente adiado até que, pela Lei n. -13.887 de 2019, sancionada pelo presidente Bolsonaro, deixou de existir um prazo limite para a obtenção do cadastro. Obviamente, esta decisão afasta ainda mais o país de cumprir as 12 metas do ODS 15 (Vida Terrestre), mas também nos afasta de assegurar padrões de produção e consumo sustentáveis (ODS 12), e de mitigar as causas das mudanças climáticas (ODS 13). Indiretamente, pelo assoreamento e pela poluição dos rios, impactam também na conservação dos oceanos, dos mares e dos recursos marinhos (ODS 14).

\section{RECURSOS PESQUEIROS}

A governança da pesca passou por vários avanços e retrocessos desde a promulgação da Constituição Federal de 1988, que estipula competir "à União, aos Estados e ao 
Distrito Federal legislar concorrentemente sobre a pesca". Nas últimas duas décadas, a responsabilidade pela gestão da pesca na arena federal transitou por diversas agências deixando clara a tensão entre esforços de conservação dos recursos pesqueiros e de crescimento da economia pesqueira (Seixas, Davidson-Hunt, Kalikoski, Davy, Berkes, de Castro et al., 2019).

O IBAMA foi responsável, desde sua criação até 1998, pela regulamentação da pesca, tanto industrial como artesanal e amadora. Embora herdando uma postura centralizadora e de comando-e-controle da SUDEPE, a gestão da pesca pelo IBAMA passou a ser guiada por comitês técnico-científicos. Em 1998, foi criado o Departamento de Pesca e Aquicultura (DPA) do Ministério da Agricultura. Desde então, o IBAMA passou a regulamentar, principalmente, as espécies sobre-exploradas (i.e., com foco na conservação) enquanto o DPA, transformado em 2003 na Secretaria Especial de Aquicultura e Pesca (SEAP) da Presidência da República, e posteriormente (2009-2015) no Ministério da Pesca e Aquicultura (MPA), passou a regulamentar as espécies sub-exploradas com potencial econômico.

Desde a extinção do MPA em 2015, a gestão da pesca passou por diversas instâncias: Ministério da Agricultura, Pecuária e Abastecimento (MAPA) (2015-2017), Ministério da Indústria, Comércio Exterior e Serviços (MDIC) (2017-2018), SEAP/PR (2018), e novamente ao MAPA (desde o início de 2019), indicando a vulnerabilidade do setor, que, segundo o Boletim do Registro Geral da Pesca (Brasil, 2012), contava com mais de 1 milhão de pescadores profissionais (sendo menos de $1 \%$ atuante na pesca industrial), contribuindo para a renda de cerca de $3 \mathrm{mi}-$ Ihões de brasileiros.

Em 2009, na tentativa de alinhar melhor os esforços de conservação e desenvolvimento da atividade pesqueira, foi emitido o Decreto n. ${ }^{\circ} 6.981 / 2009$, sobre a atuação conjunta do MPA com o Ministério do Meio Ambiente (MMA) nos aspectos relacionados ao uso sustentável dos recursos pesqueiros. $\mathrm{E}$ neste contexto foi promulgada a nova Política Nacional para o Desenvolvimento da Aquicultura e da Pesca (Lei n. 11.959/2011) - revogando o Código da Pesca (Decreto n.ำ 221/1967) criado pela SUDEPE. Uma análise da política pesqueira federal do período (2003-2011) por Azevedo \& Pierri (2014: pág.61), indica que o governo federal "favoreceu mais a aquicultura que a pesca extrativa e, dentro desta, mais a pesca industrial que a artesanal."

O setor pesqueiro é composto por diversas organizações da sociedade civil e empresariais, além de Colônias de Pescadores (Lei n. $-11.699 / 2008$ ), que é a entidade de classe reconhecida pelo Estado. Desde a década de 1970, tem ocorrido um fortalecimento das bases comunitárias da pesca artesanal, através da atuação da Pastoral da Pesca, do Movimento Nacional dos Pescadores (Monape), e mais recentemente do Movimento de Pescadores e Pescadoras Artesanais (MPP), Comissão Nacional para o fortalecimento das Reservas Extrativistas e dos povos extrativistas costeiros e marinhos (Confrem), entre outros.

\section{Avanços}

Desde a década de 1990, o Brasil apresentou avanços no reconhecimento dos usu- 
ários como importantes atores na gestão pesqueira e na legitimação das práticas tradicionais de manejo dos recursos (Vieira, dos Santos \& Seixas, 2015). A legalização pelo Estado dos Acordos de Pesca (IN IBAMA 29/2002) ocorridos entre pescadores de lagos da Amazônia é um exemplo deste reconhecimento. Os avanços também aconteceram em arenas diretamente relacionadas aos recursos pesqueiros, como o Plano Nacional de Gerenciamento Costeiro, a Política Nacional para os Recursos do Mar e o Sistema Nacional de Unidades de Conservação (Kalikoski, Seixas \& Almudi, 2009).

Com base na Política Nacional para o Desenvolvimento da Aquicultura e da Pesca, foram criados, através de portarias interministeriais (MPA/MMA), grupos de trabalho técnicos e comitês de gestão para o ordenamento do uso de recursos específicos (ex., sardinha-verdadeira, lagosta, peixes demersais). Estes grupos contavam com representantes do governo, do setor pesqueiro e cientistas.

Entre início dos anos 1990 e meados da década de 2010, vários instrumentos criados para melhor gestão da pesca e conservação dos recursos pesqueiros possuem relação direta com os ODS 1 (Erradicação da Pobreza), ODS 2 (Fome Zero) e ODS 14 (Vida na Água). Entre eles, podemos citar: o seguro-defeso (Lei n.o 8.287/1991) para pescadores em épocas de proibição da pesca de certas espécies; o Conselho Nacional de Aquicultura e Pesca, criado em 2003; o Registro Geral da Pesca (IN MPA 3/2004) -primeiro esforço nacional de contabilizar os pescadores e emitir licença de pesca para todas as categorias do setor; o Programa Nacional de Rastreamento de Embarcações
Pesqueiras por Satélite (PREPS) (IN Interministerial 2/2006 SEAP/PR, MMA e Marinha do Brasil), e a lista vermelha de 475 espécies de peixes e invertebrados marinhos e de água-doce ameaçados de extinção (Portaria MMA 445/2014).

Em termos de avanços na governança da pesca artesanal (ou de pequena escala), encontramos diversas iniciativas de gestão comunitária e/ou compartilhada da pesca em todas as regiões do Brasil (Kalikoski et al., 2009, Seixas et al., 2019).

\section{Limitações e retrocessos}

Desde a criação do MPA, o Brasil deixou de monitorar o desembarque pesqueiro de forma sistemática, sendo os últimos dados de censo pesqueiro nacional referentes a 2008. Sem monitoramento, é impossível estabelecer um ordenamento pesqueiro que seja sustentável e contribua para a Agenda 2030. Uma das primeiras medidas do atual governo foi transferir para o MAPA todas as atribuições do ordenamento pesqueiro. Em abril de 2019, o MAPA pediu ao MMA para suspender a lista de espécies ameaçadas de extinção. No mesmo mês, o Decreto $\mathrm{n}$. 9.759/2019 extinguiu e estabeleceu diretrizes, regras e limitações para colegiados da administração pública federal, comprometendo diretamente os grupos de trabalho e comitês de gestão da pesca, sendo os Comitês Permanentes de Gestão da Pesca (CPGs) extintos em junho do mesmo ano. Neste mote, a governança da pesca do Brasil atual, na contramão da governança ambiental com vistas à Agenda 2030, tem colocado seu foco no crescimento da pesca industrial, aquicultura e pesca esportiva, em detrimento do uso sustentável de espécies e 
da pesca artesanal.

\section{ÁGUA E RECURSOS HÍDRICOS}

No Brasil, a governança das águas enfrenta uma responsabilidade excepcional: gerir cerca de $12 \%$ do total de água doce superficial do planeta. A governança da água está enquadrada em um conjunto de disposições constitucionais distribuídas de forma esparsa ao longo do texto da Constituição Federal de 1988. A água é bem de domínio público e objeto de competências explícitas relacionadas a diversos aspectos: alocação para atividades e serviços; abastecimento para fins de consumo humano; exploração de recursos hídricos; água enquanto integrante do meio ambiente; e como objeto de direitos individuais e coletivos. Cabe à União a competência para instituir o sistema de gerenciamento de recursos hídricos.

Sobre estas disposições constitucionais, foram instituídas políticas e regulações setoriais sobre a água nas áreas de meio ambiente, gerenciamento de recursos hídricos, saneamento, saúde, defesa civil e desastres e, mais recentemente, a área de segurança hídrica. Além destas regulações setoriais, a governança da água é diretamente influenciada por políticas setoriais da agricultura, energia, mineração e uso do solo. A atual ordem constitucional desenha, pois, um complexo arranjo de políticas públicas, organizações e atores, envolvendo diretamente os diversos setores da sociedade civil, o setor privado, o Ministério Público e as três esferas governamentais. Para fins desta seção, será considerado o recorte referido à alocação da água para atividades e serviços e ao gerenciamento de recursos hídricos.
O Sistema Nacional de Gestão de Recursos Hídricos (SINGREH) e a Política Nacional de Recursos Hídricos (PNRH), fortemente influenciados pelo sistema francês de gestão hídrica, foram instituídos quase uma década após a promulgação do texto constitucional, regulamentando as competências constitucionais sobre o domínio e a gestão das águas e estruturando o sistema de gerenciamento de recursos hídricos (Lei n.ำ 9.433/1997).

\section{Avanços}

Ao longo de duas décadas, a implementação da PNRH e do SINGREH conquistou importantes avanços, apoiados em sólido arcabouço constitucional, regulações e arranjos institucionais. A Agência Nacional das Águas (ANA) publica relatórios de acompanhamento sistemático sobre a situação dos recursos hídricos no país e indicadores sobre sua gestão (ANA, 2018).

Vale ressaltar a participação da sociedade civil nos Comitês de Bacias Hidrográficas $(\mathrm{CBH})$ que possuem, entre outras atribuições, a obrigação de articular os diversos agentes e atuar em primeira instância em caso de conflitos. A descentralização da gestão para o nível local gerou uma mudança de paradigma de gestão deste recurso de uso comum.

Em resposta às crises hídricas, vividas nas diversas regiões do país na segunda metade da década passada, foram dados passos importantes para a estruturação de uma política de segurança hídrica, entre os quais estão o Monitor das Secas, ferramenta de integração de dados e informações geradas por diversas organizações estaduais e federais; a instituição de termos de alocação negociada da 
GOVERNANÇA AMBIENTAL NO BRASIL: RUMO AOS OBJETIVOS dO DESENVOLVIMENTO SUSTENTÁVEL (ODS)?

água (35 consolidados em 2017); o Projeto Reuso; e o lançamento, em 2019, do Plano Nacional de Segurança Hídrica (ANA, 2019). Finalmente, merecem destaque dois trabaIhos da ANA. O primeiro refere-se à articulação entre a regulação do uso da água e a regulação do saneamento, buscando inserir nas outorgas para esgotamento sanitário as metas de cobertura de rede e de eficiência de tratamento assumidas nos contratos e nos planos de saneamento básico municipais. O segundo diz respeito à contribuição ao processo de monitoramento das oito metas do ODS 6, com base em informações produzidas e sistematizadas para cálculo dos indicadores, em parceria com diversas instituições.

\section{Limitações e retrocessos}

No que diz respeito às limitações do sistema de gerenciamento de recursos hídricos stricto sensu, segundo especialistas da área (Pagnocheschi, 2016; World Bank Group, 2018; ANA, 2019), os principais desafios referem a: posição desprestigiada da gestão de recursos hídricos na agenda política nacional; dificuldades de coordenação federativa, especialmente em situações de crise; frágil integração da gestão de recursos hídricos com as demais políticas setoriais, com destaque para as políticas ambiental, de saneamento e prevenção de desastres - predominando até o momento a precariedade nas regras de compartilhamento e cooperação (em especial, falta de clareza nas atribuições em situações de duplo domínio dos recursos hídricos); melhoria de eficácia dos órgãos gestores estaduais, do $\mathrm{CNRH}$, dos $\mathrm{CBHs}$ e das Agências de Águas; e necessidade de reconhecimento de outras unidades territoriais mais adequadas às singu- laridades da gestão dos recursos hídricos, além da bacia hidrográfica.

No que diz respeito aos poderes locais, há um contraste flagrante entre a ausência dos municípios nos sistemas de gerenciamento de recursos hídricos stricto sensu e seu papel protagonista na provisão de serviços de saneamento. Nos tempos atuais, promover o debate sobre segurança hídrica - com vistas ao ODS 6 e ODS 3.9 (referentes à redução de mortes por poluição da água) -- pressupõe o enfrentamento dos vários desafios acima postos.

Retrocessos, intencionalmente promovidos desde o início de 2019, como a transferência do SINGREH do MMA para o Ministério do Desenvolvimento Regional, vêm dificultando a integração com o setor ambiental, ameaçando o sistema de governança das águas construído ao longo das últimas duas décadas, destruindo capacidades técnicas e institucionais que são patrimônio coletivo e agravando os processos de deterioração do patrimônio hídrico e de seu sistema de gestão.

\section{UNIDADES DE CONSERVAÇÃO}

No conjunto dos objetivos da Agenda 2030, a conservação e o uso sustentável dos oceanos, dos mares e dos recursos marinhos para o desenvolvimento sustentável (ODS 14) e a proteção, recuperação e promoção do uso sustentável dos ecossistemas terrestres (ODS 15) perpassam necessariamente pela governança das Unidades de Conservação (UCs).

As discussões em torno da necessidade de um sistema brasileiro único de áreas prote- 
gidas foram sendo tratadas a partir da década de 1970, mas consolidadas em um Projeto de Lei apenas em 1992 (PL n.․ 2.892/92) (Medeiros, 2006). Nos oito anos seguintes, o arranjo institucional mais importante das UCs foi disputado, especialmente, entre interesses de preservacionistas, socioambientalistas e ruralistas (Medeiros, 2006; Ramos, 2014). Entre as principais polêmicas, destacava-se o conceito de população tradicional e sua presença nas UCs, a necessidade de envolvimento da sociedade na sua criação, a pertinência de determinadas categorias, e a sobreposição com terras indígenas (Ranieri et al., 2011).

O Sistema Nacional de Unidades de Conservação (SNUC - Lei $\mathrm{n}$. 9 9.985/2000) e seu decreto complementar (Decreto n.․ 4.340/2002) nascem, portanto, do embate entre múltiplos atores e paradigmas inerentes à compreensão sobre conservação, a relação entre sociedade e natureza, e sobre desenvolvimento econômico nacional (Barreto-Filho, 2006). Parte da disputa entre paradigmas de conservação e desenvolvimento é observada nas 12 diferentes categorias de unidades, divididas entre Proteção Integral ou Uso Sustentável (Pecatiello, 2011).

Após o SNUC, inúmeros outros arranjos formais também passaram a regulamentar temas associados às UCs. Entre eles, podemos mencionar a Política Nacional da Biodiversidade (Decreto n.. 4.339/2002); o Plano Estratégico Nacional de Áreas Protegidas (Decreto n.․ 5.758/2006); a Política Nacional de Desenvolvimento Sustentável dos Povos e Comunidades Tradicionais (Decreto n. 6.040/2007), a Política Nacional de Gestão Territorial e Ambiental de Terras Indígenas (Decreto n. 7.747/2012), além de inúmeras instruções normativas e portarias que regulamentam ou já regulamentaram procedimentos relativos às UCs.

Uma alteração substancial na governança das áreas protegidas, na década de 2000 , deu-se com a criação do Instituto Chico Mendes de Conservação da Biodiversidade (ICMBio), em 2007. O ICMBio é a autarquia que passou a gerir as UCs federais, fomentar e executar programas de pesquisa, proteção, preservação e conservação da biodiversidade. O IBAMA, que tinha até então essa atribuição, passou a concentrar sua atuação no licenciamento ambiental, controle da qualidade ambiental, autorizações de uso de recursos naturais e fiscalizações. É importante mencionar que, para alguns, a divisão do IBAMA e a criação do ICMBio foram medidas polêmicas (Ramos, 2014).

\section{Avanços}

Além das grandes políticas ou dos programas nacionais que tangenciam a temática das UCs, outros arranjos formais trouxeram avanços consideráveis no detalhamento de procedimentos e instrumentos de gestão, como instruções normativas e portarias nas três esferas governamentais. Talbot (2016) destaca avanços relacionados ao fomento à maior participação social na criação e gestão das áreas e o reconhecimento de situações de conflitos territoriais entre as diversas categorias de UCs.

Os conselhos gestores, por exemplo, representam, hoje, o principal arranjo institucional para a participação social nas UCs. São reconhecidos como instrumentos importantes de fortalecimento democrático e aproximação da sociedade na gestão ambiental pública e 
em pautas como conservação da biodiversidade. Em 2017, das 322 UCs federais, 281 tinham conselho instituído (Painel Dinâmico do ICMBio, 2019).

Os termos de compromisso também são instrumentos formais previstos no SNUC, destinados a regular o uso dos recursos naturais e as condições de permanência de comunidades tradicionais em UCs de proteção integral. Embora seja um instrumento de caráter transitório, é possível observar suas potencialidades na gestão de conflitos históricos, proporcionados pelo estabelecimento unilateral de UCs em territórios tradicionais (Talbot, 2016). Sua implementação ainda é controversa e rodeada por longas disputas internas nos órgãos ambientais. No entanto, trata-se de um instrumento relevante, que vai ao encontro da meta nacio- nal de biodiversidade de, até 2030, respeitar "os conhecimentos tradicionais, inovações e práticas de povos indígenas, agricultores familiares e comunidades tradicionais relevantes à conservação e uso sustentável da biodiversidade, e a utilização consuetudinária de recursos biológicos" (IPEA, 2018: pág. 393).

A criação de novas UCs (Figura 1) também vem sendo vislumbrada como meta no conjunto de políticas e acordos internacionais. Nessa perspectiva, em 2018 o Brasil cumpriu a Meta de Aichi estabelecida pela Convenção sobre Diversidade Biológica (CDB) para proteger $10 \%$ das áreas marinhas e costeiras até 2020, bem como o ODS 14.5. Com isso, o Brasil passou de 1,5\% de áreas marinhas protegidas para $25 \%$.

Figura 1. Número de hectares protegidos com a criação de UCs Federais desde a década de 1930

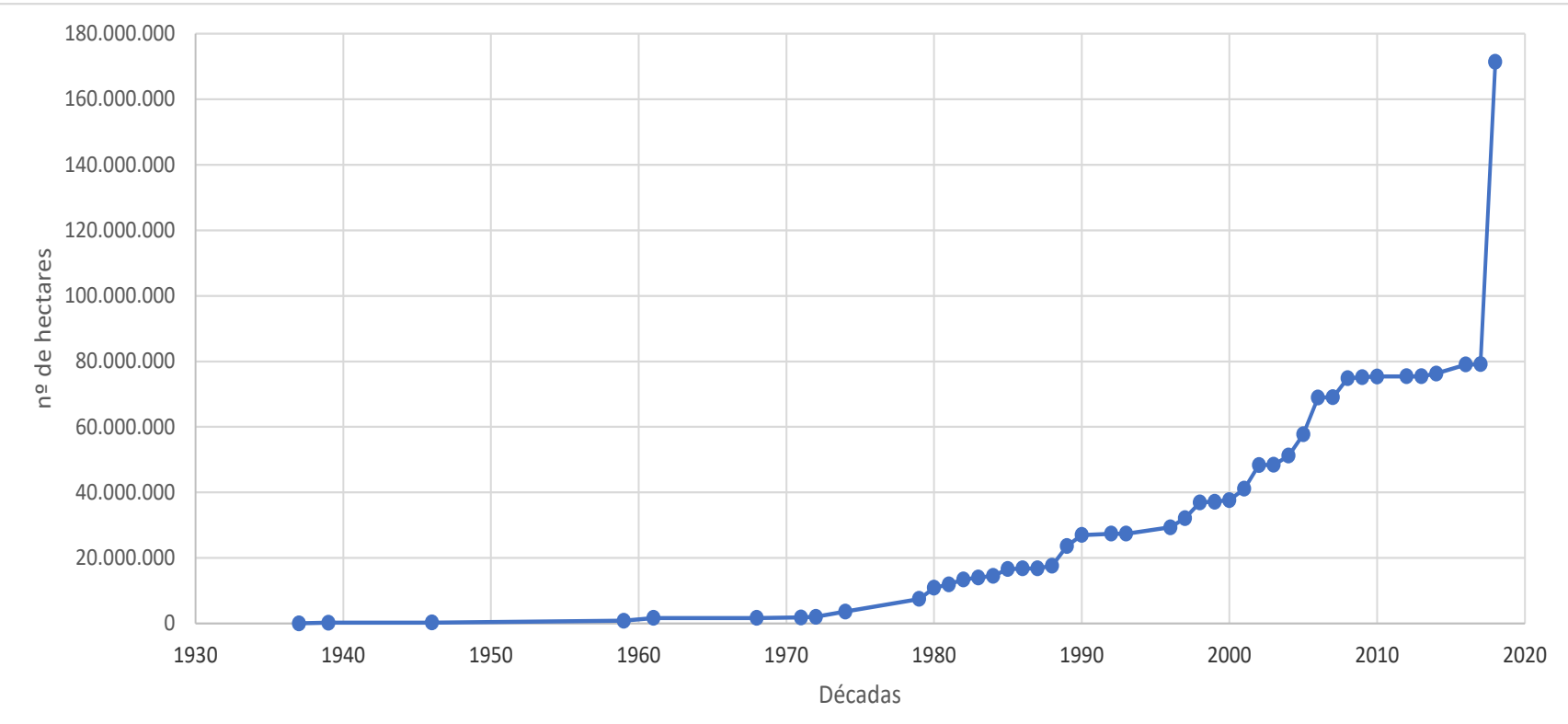

Fonte: Painel Dinâmico do ICMBio (2019). 
Cristiana Simão Seixas - Deborah Santos Prado - Carlos Alfredo Joly - Peter Herman May - Estela M. Souza Costa Neves - Leonardo Ribeiro Teixeira

É importante salientar ainda que grande parte dos avanços em arranjos formais é derivada de pressões políticas, de movimentos sociais de base, ambientalistas, servidores públicos e outros stakeholders. Todavia, embora tenhamos um avanço considerável, a eficiência e efetividade dos instrumentos formais rumo aos ODS relacionam-se com as dinâmicas de poder de cada região do país.

\section{Limitações e retrocessos}

A conjuntura política brasileira atual é desfavorável para a governança de UCs rumo aos ODS. Observam-se retrocessos claros no reforço à dicotomia entre conservação e desenvolvimento, e na diminuição dos espaços de participação social. O país retrocede ao considerar as UCs como vilãs do crescimento econômico. Acentuam-se, assim, as dificuldades em promover a regularização fundiária, a consolidação territorial e a fiscalização efetiva em inúmeras UCs.

Enquanto o ODS 15.2 nos coloca o desafio de, até 2020, "promover a implementação da gestão sustentável de todos os tipos de florestas, deter o desmatamento, restaurar florestas degradadas e aumentar substancialmente o florestamento e o reflorestamento globalmente," nós respondemos com o alarmante aumento do desmatamento na Floresta Amazônica em 29,54\% no ano de 2019 (PRODES, 2019).

Ainda que o financiamento internacional tenha impulsionado o orçamento de muitas UCs, o sucateamento estrutural dos órgãos ambientais compromete, consideravelmente, o desempenho das áreas. O ICMBio, por exemplo, apresenta sérias limitações estruturais e de recursos humanos. O órgão declara possuir, em 2020, um total de 1.463 servidores (Painel Dinâmico do ICMBio, 2020). Em 2008, quando havia quase 100 milhões ha a menos de UCs do que em 2020, o número de servidores da autarquia era de 1.786 (Maretti, 2018). A escassez de recursos financeiros e humanos é um gargalo que percorre os 20 anos de história do SNUC. O mero incremento numérico de UCs não cumprirá os objetivos das áreas protegidas, se elas não forem de fato implementadas em todas as suas dimensões.

Além disso, os processos de redução de tamanho, recategorização ou desafetação de UCs (conhecido por PADD - Protected Areas downgrading, downsizing, and degazettement) vêm sendo intensificados e representam ameaças concretas às áreas protegidas. No bioma Amazônia, por exemplo, ocorreram 46 eventos de PADD entre 1988 e 2018, totalizando 14 exclusões, cinco mudanças de categoria e 27 reduções de áreas, que afetaram 37 UCs (WWF, 2019).

O caminho rumo aos ODS requer uma rápida e definitiva mudança de paradigma no campo da governança ambiental de UCs, que supere a dicotomia entre conservação e desenvolvimento ou sociedade versus natureza, e que considere a complexidade socioambiental e as metas de longo prazo.

\section{MUDANÇAS CLIMÁTICAS}

A política nacional brasileira de mudanças climáticas surgiu com a ratificação pelo país da Convenção-Quadro das Nações Unidas sobre Mudança do Clima (UNFCCC) em 1994, que estabeleceu o marco para os países signatários cooperarem para alcançar 
a redução de emissões de gases de efeito estufa (GEE) e acessarem recursos e assistência técnica.

Em 2007, quando foi entregue o primeiro relatório setorial de emissões de GEE à UNFCCC, ficou claro que as principais emissões do Brasil - em contraste com os países do Norte -- eram causadas mais por mudanças no uso da terra e das florestas através do desmatamento, do que por energia, indústria e transporte. Mesmo assim, as emissões do setor energético cresceram ao longo de 1990-2017, apesar de. haver uma redução nestas emissões a partir de 2015 com a ampliação do mercado de energia eólica e solar, incentivados pela criação do Programa de Incentivo às Fontes Alternativas de Energia Elétrica.

Quanto ao uso da terra, as pressões principais advêm da agropecuária (SEEG, 2019), fazendo o Brasil um dos países com a maior emissão de GEE no planeta. Controlar o uso da terra exige a aplicação efetiva da LPVN e do SNUC, instrumentos essenciais na manutenção dos estoques de carbono existentes nas florestas remanescentes. O Plano de Prevenção e Controle de Desmatamento na Amazônia (PPCDAm), implantado em 2005, e coordenado pela Casa Civil e pelo MMA resultou num êxito inicial em reduzir as emissões, que declinaram rapidamente até 2012.

\section{Avanços}

O Plano Nacional sobre Mudanças Climáticas, apresentado em 2008 (PNMC, Decreto n. ${ }^{\circ} 6.263 / 2008$ ) e a Política Nacional de Mudanças Climáticas (PNMC) adotada por lei no ano seguinte (Lei n. 12.187/2009), e regulamentada por decreto em 2010 (Decreto $\mathrm{n} . \mathrm{o} 7.390 / 2010$ ) regulamentam a resposta brasileira às mudanças climáticas. A PNMC definiu a elaboração e implementação de planos de prevenção e controle do desmatamento por bioma, e mitigação de emissões setoriais, assim como um plano nacional de adaptação climática. O Fundo Nacional de Mudanças Climáticas (FNMC) aporta recursos necessários para cumprir com os planos definidos.

A PNMC é composta de um conjunto de programas e planos, incluindo os planos setoriais e por bioma, o Plano Nacional de Adaptação e a Estratégia Nacional de Redução de Emissões do Desmatamento e Degradação Florestal (REDD+), sob a coordenação de um Grupo Executivo sobre Mudança do Clima (GEx) e do Comitê Interministerial sobre Mudança do Clima (CIM). A complexidade das ações transversais e multiníveis para seu alcance levou ao reconhecimento da necessidade de envolver e articular as ações dos ministérios com os níveis subnacionais, para ajudar a alcançar os resultados previstos pelo PNMC. Em 2009, o Brasil apresentou sua intenção de reduzir as emissões em até 38,9\% da linha de base ("business-as-usual"), na 15. a Conferência das Partes (COP) da UNFCCC.

Apesar do afrouxamento regulatório da LPVN em 2012, as Contribuições Nacionalmente Determinadas (NDCs) do Brasil apresentadas para compor o Acordo de Paris de 2015 implicaram no compromisso de reduzir $37 \%$ das emissões de todas as fontes até 2025, com referência à linha de base de 2005 (Brasil, 2015). Os compromissos brasileiros incluíram a restauração líquida de 12 milhões ha de terras degradadas e a ado- 
ção de uma meta de "desmatamento ilegal zero" até 2030. Estas metas foram formalizadas na Política de Restauração de Vegetação Nativa (Proveg) através do Decreto $\mathrm{n}$. o 8.972/2017 e respectivo plano (Planaveg) que visa a estruturar cadeias de serviços para restauração de vegetação nativa.

Os mecanismos de compensação por manutenção de carbono na paisagem surgiram, muitas vezes, através de projetos-piloto estruturados por ONGs em parceria com produtores rurais, governos municipais e outras entidades (Pagiola, Von Glehn, \& Taffarello, 2013). Alguns esforços bem-sucedidos de restauração florestal foram estimulados por meio de Pagamentos por Serviços Ambientais (PSA), adotados cada vez mais no Brasil como forma de incentivar a maior participação de proprietários privados. Além disso, constatam-se esforços para precificar o carbono, bem como compromissos corporativos e setoriais para reduzir voluntariamente suas emissões (Serôa da Motta, 2016).

O Programa Nacional de Agricultura de Baixo Carbono (Plano ABC), desde 2011 fornece empréstimos a uma baixa taxa de juros aos agricultores para reformar pastagens $\mathrm{e}$ adotar sistemas integrados de uso da terra, marcando alguns avanços. Desses créditos, houve maior contratação nos Estados do Sul/Sudeste e do Centro-Oeste (MAPA, 2018). Atualmente, estima-se que sistemas integrados de produção agropecuária-florestal tenham sido estabelecidos em mais de 11,5 milhões ha em todo o país, a maioria no bioma Cerrado (Embrapa, 2018).

A sociedade civil desempenhou um papel fundamental na implementação da agenda de mudanças climáticas no Brasil, com crescente envolvimento através de redes como o Observatório do Clima e o Fórum Brasileiro de Mudanças Climáticas, criado no bojo do PNMC para assessorar a presidência. Além de aglutinar forças de diversos segmentos na sociedade, tais redes lançaram importantes iniciativas e bancos de dados de acesso aberto, tais como o Sistema de Estimativas de Emissões de Gases de Efeito Estufa (SEEG), criado em 2018 pelo Observatório do Clima para produzir suas próprias estimativas anuais de emissões de gases de efeito estufa no Brasil. Também tem surgido coalizões empresariais junto às ONGs, como a Coalizão Clima, Florestas e Agricultura, fortalecendo a pluralidade dos processos democráticos e participativos na tomada de decisão.

\section{Limitações e retrocessos}

A atual tendência da política governamental, porém, tem revertido os avanços descritos, reduzindo drasticamente a representação da sociedade civil nas instâncias consultivas e ameaçando a saída do Brasil do Acordo de Paris em resposta às críticas que o país tem recebido em fóruns internacionais devido ao recrudescimento do desmatamento e das queimadas na Amazônia. As tentativas de alertar para as vantagens do comércio com a Comunidade Europeia, e de evidenciar o apoio às práticas produtivas sustentáveis como chave para o acordo com Mercosul têm sido sufocadas por argumentos sobre a necessidade de proteção da soberania e autodeterminação no uso dos recursos naturais. E mesmo com os avanços observados, o esforço de redução de emissões através de medidas de comando e controle vem diminuindo devido às flexibilizações ocorridas pela adoção da LPVN em 2012 (Brancalion 
GOVERNANÇA AMBIENTAL NO BRASIL: RUMO AOS OBJETIVOS DO DESENVOLVIMENTO SUSTENTÁVEL (ODS)?

et al., 2016), representando um "tiro no pé" do próprio agronegócio (May et al., 2019). A perda do papel de vanguarda e proatividade do Brasil nos fóruns globais deixa nebuloso o potencial de reversão deste quadro no regime atual.

\section{RUMO À AGENDA 2030?}

Desde a Constituição Federal de 1988, o Brasil produziu várias políticas públicas e instrumentos de gestão na área ambiental e movimentos sociais emergiram em diversos setores - ampliando a participação da sociedade nas tomadas de decisão. Grande parte das políticas e instrumentos aqui apresentados, mesmo que imperfeitos e implementados dentro de uma lógica setorizada, demonstraram avanços na governança ambiental do país em direção à Agenda 2030. A grande maioria desses avanços deu-se devido à participação da sociedade civil e de representantes da ciência brasileira nos fóruns de discussão para a construção - e em muitos casos implementação - destas políticas e destes instrumentos.

A influência internacional (incluindo acordos e demandas de mercados externos) e as conjunturas políticas e econômicas internas (incluindo o fortalecimento do setor privado com propostas pragmáticas) também explicam avanços e retrocessos na governança ambiental do país (Castro \& Futemma, 2015). As disputas inerentes entre conservação e crescimento mostram que os avanços normativos construídos a duras penas são ainda muito frágeis.

Segundo o III Relatório Luz da Sociedade Civil da Agenda 2030 (2019), páginas no site do MMA foram retiradas do ar (in- cluindo as áreas prioritárias para conservação da natureza) e o presidente Bolsonaro efetivou o "revogaço", anulando decretos por serem considerados "desnecessários" A Política Nacional de Participação Social, criada em 2014, foi revogada pelo Decreto n. 9 9.759/2019, que também prevê a extinção de inúmeros colegiados. O CONAMA sofreu forte golpe com a alteração de sua composição, excluindo as sociedades científicas e restando apenas quatro cadeiras à sociedade civil (Decreto n. 9.806/2019). Essas medidas, entre outras apresentadas neste trabalho, exemplificam uma iniciativa de esvaziamento do controle social, institucionalizado a partir de disputas e conquistas dos movimentos sociais desde a década de 1990. Além disto, expõem a desvalorização do saber científico, como relatado em diversos artigos da Coalização Ciência \& Sociedade (http://cienciasociedade.org/).

Outros destaques do "revogaço" incluem: a extinção no MMA dos setores de mudanças climáticas, recursos hídricos e florestas públicas; a paralisação do Fundo Amazônia e de criação de UCs (além do PADD); e o estímulo ao desmatamento, às queimadas, à extração ilegal de madeira, ao garimpo clandestino e à ocupação ilegal de terras indígenas e UCs. Observa-se, ainda, o esvaziamento das equipes de fiscalização do IBAMA e do ICMBio, os ataques aos acordos sobre mudança do clima, as iniciativas de desmonte do sistema de licenciamento ambiental e, finalmente, o veto ao monitoramento dos ODS no Plano Plurianual 20202023.

Os retrocessos impostos ao sistema de governança ambiental na última década, $\mathrm{e}$ principalmente no último ano, indicam que 
o país caminha na direção oposta ao futuro almejado pela Agenda 2030. Vale ressaltar que os pactos e acordos internacionais contribuem para os arranjos de governança das nações, mas não têm sido suficientes para protagonizar as transformações urgentes e necessárias frente à crise ambiental planetária.

\section{REFERÊNCIAS}

ANA - Agência Nacional das Águas (2018). Conjuntura dos recursos hídricos no Brasil 2018: informe anual. Recuperado de http:// arquivos.ana.gov.br/portal/publicacao/Conjuntura2018.pdf

ANA - Agência Nacional de Águas (2019). Plano Nacional de Segurança Hídrica. Brasília: ANA. Recuperado de http://arquivos. ana.gov.br/pnsh/pnsh.pdf.

Azevedo, N. T. \& Pierri, N. (2014). A política pesqueira no Brasil (2003-2011): A escolha pelo crescimento produtivo e o lugar da pesca artesanal. Desenvolvimento e Meio Ambiente, 32. http://dx.doi.org/10.5380/dma. v32i0.35547

Barreto Filho, H. T. (2006). Populações tradicionais: Introdução à crítica da ecologia política de uma noção. In C. Adams, R.S.S. Murrieta; W.A. Neves (eds.). Sociedades caboclas amazônicas: Modernidade e invisibilidade. São Paulo: Annablume, pp. 109-144

Beck, U., Lash, S., \& Wynne, B. (1992). Risk society: Towards a new modernity. Sage.

BPBES 2018, Diagnóstico brasileiro sobre biodiversidade e serviços ecossistêmicos: Sumário para tomadores de decisão. In ht- tps://www.bpbes.net.br/produto/diagnostico-brasileiro/.

Brancalion, P. H., Garcia, L. C., Loyola, R., Rodrigues, R. R., Pillar, V. D., \& Lewinsohn, T. M. (2016). Análise crítica da Lei de Proteção da Vegetação Nativa (2012), que substituiu o antigo Código Florestal: Atualizações e ações em curso. Natureza \& Conservação, 14, e1-e16. https://doi.org/10.1016/j. ncon.2016.03.004

Brasil (2012). Ministério da Pesca e Aquicultura. Boletim de Registro Geral da Atividade Pesqueira, 50p.

Brasil. (2015). Intended Nationally Determined Contribution Towards Achieving the Objective of the United Nations Framework Convention on Climate Change. Recuperado de https://www4.unfccc.int/sites/ndcstaging/ PublishedDocuments/Brazil\%20First/BRAZIL\%20iNDC\%20english\%20FINAL.pdf.

Castro, F. \& Futemma, C. 2015 Introdução. In F. Castro \& C. Futemma. Governança Ambiental no Brasil - entre o socioambientalismo e a economia verde. Editora Paco/FAPESP.

CEBDS (2019). Contribuições para o debate sobre a melhoria da gestão do Licenciamento Ambiental Federal. Rio de Janeiro: ConseIho Empresarial Brasileiro para o Desenvolvimento Sustentável (CEBDS).

Chuenpagdee, R., \& Jentoft, S. (2009). Governability assessment for fisheries and coastal systems: A reality check. Human Ecology, 37(1), 109-120. https://doi.org/10.1007/ s10745-008-9212-3

Dias, M. A., \& Machado, E. L. (2007). Prin- 
cípios do Equador: Sustentabilidade e Impactos na conduta ambiental dos bancos signatários brasileiros. Pontifícia Universidade Católica de São Paulo. São Paulo.

Drummond, J. A. (1999). A legislação ambiental brasileira de 1934 a 1988: Comentários de um cientista ambiental simpático ao conservacionismo. Ambiente \& sociedade, 3(4), 127-149.

Embrapa. (2018). ILPF em números. Recuperado de https://ainfo.cnptia.embrapa.br/ digital/bitstream/item/158636/1/2016-cpamt-ilpf-em-numeros.pdf

Folke, C., Hahn, T., Olsson, P., \& Norberg, J. (2005). Adaptive governance of social-ecological systems. Annu. Rev. Environ. Resour., 30, 441-473. https://doi.org/10.1146/annurev. energy.30.050504.144511

Fonseca, A., Sánchez, L. E., \& Ribeiro, J. C. J. (2017). Reforming EIA systems: A critical review of proposals in Brazil. Environmental Impact Assessment Review, 62, 90-97. https://doi.org/10.1016/j.eiar.2016.10.002

Fonseca, A., Sánchez, L. E., Montano, M., Souza, M. M. P. D., \& Almeida, M. R. R. (2019). Proposta de lei geral do Licenciamento Ambiental: Análise crítica e propositiva do projeto de lei à luz das boas práticas internacionais e da literatura científica. Waterloo, CA: School of Environment, Resources and Sustainability, University of Waterloo.

Guidotti, V., Freitas, F. L., Sparovek, G., Pinto, L. F. G., Hamamura, C., Carvalho, T., \& Cerignoni, F. (2017). Números detalhados do novo código florestal e suas implicações para os PRAs. Sustentabilidade em debate,
$5,1-11$.

Hofmann, R. M. (2015). Gargalos do licenciamento ambiental federal no Brasil. Consultoria Legislativa. Brasília: Câmara dos Deputados.

ICMBIO. Painel dinâmico do ICMBio. Recuperado de http://qv.icmbio.gov.br/index.htm.

IPEA. (2018). Agenda 2030: ODS-Metas Nacionais dos objetivos de desenvolvimento sustentável. Recuperado de http://www. ipea.gov.br/portal/index.php?option=com content \&view $=$ article\&id $=33895 \&$ Item $i d=433$.

Kalikoski, D. C., Seixas, C. S., \& Almudi, T. (2009). Gestão compartilhada e comunitária da pesca no Brasil: Avanços e desafios. Ambiente \& Sociedade, 12(1), 151-172. https://doi.org/10.1590/S1414$-753 X 2009000100011$

Kooiman, J., \& Bavinck, M. (2005). The governance perspective. Fish for life: Interactive governance for fisheries, 3, 11. Amsterdam University Press.

Lemos, M. C., \& Agrawal, A. (2006). Environmental governance. Annu. Rev. Environ. Resour., 31, 297-325. https://doi.org/10.1146/ annurev.energy.31.042605.135621

MAPA. (2018) Plano ABC em números. Recuperado de http://www.agricultura.gov.br/ assuntos/sustentabilidade/plano-abc/plano-abc-em-numeros/plano-abc-em-numeros

Maretti, C. Sistemas de Unidades de Conservação: Desafios para sua consolidação. Encontro das Unidades de Conservação 
Cristiana Simão Seixas - Deborah Santos Prado - Carlos Alfredo Joly - Peter Herman May - Estela M. Souza Costa Neves - Leonardo Ribeiro Teixeira

Paulistas. Apresentação Oral. 2018.

May, P., Barbosa, A., Azeredo, E., Costa, F., Ramos, F., Speranza, J., \& Lanza, T. (2019). Políticas de crédito podem incentivar boas práticas na Amazônia Legal. AgroANALYSIS, 39(9), 25-26.

Medeiros, R. (2006). Evolução das tipologias e categorias de áreas protegidas no Brasil. Ambiente \& Sociedade, 9(1), 41-64. https://doi.org/10.1590/S1414$-753 \times 2006000100003$

Metzger, J. P., Bustamante, M. M., Ferreira, J., Fernandes, G. W., Librán-Embid, F., Pillar, V. D., ... \& Overbeck, G. E. (2019). Why Brazil needs its legal reserves. Perspectives in Ecology and Conservation, 17(3), 91-103. https://doi.org/10.1016/j.pecon.2019.07.002

OCDE. Organização de Cooperação e Desenvolvimento Econômico. (2012). Aplicação da Avaliação Ambiental Estratégica: Guia de Boas Práticas na Cooperação para o Desenvolvimento. OCDE Publishing. Recuperado de http://www.oecd-ilibrary.org.

Pagiola, S., Von Glehn, H. C., \& Taffarello, D. (2013). Experiências de pagamentos por serviços ambientais no Brasil. São Paulo: SMA/CBRN, 274.

Pagnoccheschi, B. (2016). Governabilidade e governança das águas no Brasil. In Moura, A. M. M. (org). Governança ambiental no Brasil: Instituições, atores e políticas públicas. Capítulo 7. Brasília: IPEA, 2016, p. 175199.

Pasqualetto, A. (2011). O 'Novo' Código Florestal Brasileiro. Revista Ecológica 3. Recu- perado de http://www.revistaecologica.com.

Peccatiello, A. F. O. (2011). Políticas públicas ambientais no Brasil: Da administração dos recursos naturais (1930) à criação do Sistema Nacional de Unidades de Conservação (2000). Desenvolvimento e Meio Ambiente, 24. DOI: http://dx.doi.org/10.5380/dma. v24i0.21542

PRODES (2019). Monitoramento do Desmatamento da Floresta Amazônica Brasileira por Satélite. Recuperado de http://terrabrasilis.dpi.inpe.br/app/dashboard/deforestation/ biomes/legal_amazon/rates.

Ramos, A. (2014). Políticas públicas para áreas protegidas no Brasil. Bensusan, N. \& Prates, A.P. A diversidade cabe na Unidade? Áreas protegidas no Brasil. IEB Mil Folhas.

Ranieri, V. E. L., Medeiros, R., Valverde, Y., D’Avignon, A., Pereira, G. S., Barbosa, J. H. C., \& Sousa, N. O. D. M. (2011). Passado, presente e futuro do sistema nacional de unidades de conservação: Uma síntese dos resultados do seminário nacional. In Medeiros,R.; Araujo, F.F.S. Dez anos do sistema nacional de unidades de conservação da natureza: Lições do passado, realizações presentes e perspectivas para o futuro. Brasília: MMA.

Sánchez, L. E., Fonseca, A., \& Montano, M. (2019). Proposta de lei geral do Licenciamento Ambiental: Análise crítica e propositiva da terceira versão do projeto de lei à luz das boas práticas internacionais e da literatura científica. Waterloo,CA: School of Environment, Resources and Sustainability, University of Waterloo. doi 10.13140/ RG.2.2.10309.81121 
SBPC, A. Sociedade Brasileira para o Progresso da Ciência, Academia Brasileira de Ciências, 2012. O Código florestal e a Ciência: Contribuições para o Diálogo. São Paulo. In http://portal.sbpcnet.org.br/publicacoes/codigo-florestal/

SEEG. Sistema de Estimativa de Emissão e Remoção de Gases de Efeito Estufa (2019) Estimativa de emissões por setor: 19902018. In http://plataforma.seeg.eco.br/total_ emission\#

Seixas, C. S., Davidson-Hunt, I., Kalikoski, D. C., Davy, B., Berkes, F., de Castro, F., ...\& Araujo, L. G. (2019). Collaborative coastal management in Brazil: Advancements, challenges, and opportunities. In Viability and sustainability of small-scale fisheries in Latin America and the Caribbean (pp. 425451). Springer, Cham.

Seixas, C. S., Vieira, P. F., Medeiros, R.P., Quevedo, P., Zerafini, T.Z. (2020). Introdução. In Seixas \& Vieira e Medeiros (Eds). Governança, conservação e desenvolvimento em territórios marinhos-costeiros no Brasil. RiMA Editora. São Carlos.
Serôa da Motta, R. (2016) Precificação do carbono na ind ústria brasileira: Uma iniciativa estratégica. Rio de Janeiro: CEBDS e CPLC.

Talbot, V. (2016). Termos de Compromisso: Histórico e perspectivas como estratégia para a gestão de conflitos em unidades de conservação federais. (Dissertação de Mestrado).

Vieira, M. A. R., dos Santos, C. R., \& Seixas, C. S. (2018). Oportunidades na legislação brasileira para sistemas de gestão compartiIhada da pesca costeira. Boletim do Instituto de Pesca, 41(4), 995-1012.

WORLD BANK GROUP. Diálogos para o aperfeiçoamento da política e do sistema de recursos hídricos no Brasil. Sumário Executivo. Banco Mundial: Brasília, junho 2018.

WWF. PADDD em unidades de conservação na Amazônia. Mapeamento e análise das tendências de redução, recategorização e extinção de unidades de conservação no bioma. 2019. 